\title{
Doing critical research in information systems: A case of theory and practice not informing each other
}

\author{
Kathy McGrath \\ Department of Information Systems and Computing, Brunel University, Uxbridge, \\ Middlesex, UB8 3PH, UK \\ e-mail: Kathy.McGrath@brunel.ac.uk
}

\begin{abstract}
For more than thirty years critical research in information systems (IS) has challenged the assumption that technology innovation is inherently desirable and hence to the benefit of all. Nevertheless, how researchers view the nature of being critical has changed over time, and so too have the ways that they pursue their critical agenda and argue for their contributions. In this paper I present a brief historical account of critical IS research, tracing the theoretical perspectives that have been dominant at different times and the empirical efforts that were guided by them. As part of tracing our current position I examine two key texts, authored by Chrisanthi Avgerou and Geoff Walsham, who pursue different types of critical agenda and make distinctive empirically-based contributions concerning the substantive issue of global diversity in IS innovation and its consequences. Overall, I suggest that the IS field now accepts broad definitions of the nature of being critical, but despite having a body of empirical critical research from which to learn, we are not making the most of our opportunities to do so, which retards further development. While I do not seek to develop a prescription for conducting and evaluating critical research, or try to encourage lengthy confessional accounts of research conduct in all journal papers, I do argue that we need more explicit reflections about our sustained long-term efforts in the field. Such reflections might consider the way we develop our critical arguments and insights, and what we strive for and accomplish through our interventions. In effect, the IS field has not yet reached a position where the theory and practice of doing critical research are informing each other.
\end{abstract}

Keywords: critical research methods, information systems, critical social theory, research practice, longitudinal case studies, ethnography.

\section{INTRODUCTION}

A growing number of information systems (IS) researchers lay claims to adopting a critical perspective. They state this on their web pages, gather at conferences dedicated to critical research, and publish work where their declared aim is to challenge dominant discourses. But what do they really mean by "being critical", how do they conduct this type of research, and in what ways might we evaluate its contribution? 
These are key epistemological and methodological questions for any research perspective and, unsurprisingly, the answers that researchers in information systems have offered to them have changed over time. Specifically, IS researchers have declared what they mean by a critical perspective (Orlikowski and Baroudi, 1991; Walsham, 2003), identified particular critical theories and concepts as promising ones for the discipline (Lyytinen, 1992; Avgerou, 2002), and argued that although there are no critical methods as such, interpretive methods can help in the field (University of Salford, 2001). Nevertheless, despite numerous calls since the 1970s for research that adopts a critical, reflexive stance on the interrelationships among information systems, organizations and society (Mumford and Sackman, 1974; Mumford et al, 1985; Nissen et al, 1991; Lyytinen, 1992; Lee et al, 1997; Adam et al, 2001; Walsham, 2003), the existing contributions are mostly conceptual. Moreover, even within the relatively small body of empirical work that has been conducted, researchers are noticeably silent about their contributions to critical research methods, so this work does not seem to be informing our research practices.

We might conclude that much empirical critical research is undertaken by engaging with critical theories and qualitative, hermeneutic (or interpretive) methods. But there is an inherent tension in adopting such an approach. Research methods informed by an interpretive stance would look for multiple interpretations and deep understanding of the often conflicting rationalities of the actors involved in IS innovation. Critical researchers, on the other hand, often have a cause - for example, feminism, environmentalism, less developed economies - so they may see a particular conflict and focus on that, downplaying other potential interpretations. With these considerations in mind, we may explore the relationship between critical and interpretive research, specifically in light of changing definitions about the nature of "being critical". We may then ask: how much have we learnt about engaging in critical research, what seem to be the prevailing practices and unresolved issues, and in what ways might further development of critical IS research take place? Overall, I argue that we have made a significant effort conceptualizing critical research, a lesser effort practising critical research, and virtually no effort reflecting upon the conduct of critical research. In effect, the IS field has not yet reached a position where the theory and practice of doing critical research are informing each other.

Following this introductory section, I discuss some key ideas and publications that have provided an ideological and theoretical basis for critical research on the interrelationships among information systems, organizations and society. Adopting an inclusive view of the nature of being critical, I examine some resources and guidance available to those who engage in critical research. Then I discuss two key texts that demonstrate different ways of pursuing a critical agenda, and ask what research practice can learn from them. I conclude with some implications for researchers doing empirical critical work.

\section{THE CHANGING NATURE OF BEING CRITICAL}

In the late 1980s, Smircich and Calas argued that the organizational culture literature 'has become dominant but dead', and asked 'what of the opposition - is it in vain?' (1987, p. 248). They suggested that a 'cultured organizational literature' - as postmodernist criticism - is how we should understand the way that organizational 
theorizing had been transformed. In essence, their argument was that the interpretivist movement in organizational culture research, which earlier had presented a substantive challenge to mainstream organizational theory, had now been absorbed into the dominant managerialist discourse. Nevertheless, they suggested that the opposition movement had paved the way for those who had been excited by it to adopt a more critical, reflexive stance within the discipline. One might ask at this point if interpretive researchers in information systems began to sense something similar at much the same time. Many IS researchers who now claim to conduct critical research would have emphasized their interpretive stance ten or fifteen years ago. Has interpretive research in information systems now been subsumed within a managerialist discourse or has the definition of critical research broadened to include interpretive work? In the following paragraphs I suggest that we can see shifts in both directions in the changes that have taken place.

\subsection{A social democratic view}

In the introduction to their forthcoming edited volume (Avgerou et al, 2004), Chrisanthi Avgerou, Claudio Ciborra and Frank Land discuss the seminal contribution made to a critical discourse within information systems by the proceedings of the Human Choice and Computers conference of 1974. In these proceedings the editors, Mumford and Sackman (1974), encouraged people in all walks of life to engage with the way that computer applications were being developed and deployed, and to make the human choices necessary to ensure that democratic values and ideals were preserved for the benefit of everyone. In such a social democratic perspective, there was a belief that humans could take deliberate action to maintain their cherished values by having these ideals incorporated into the design of computer systems. Moreover, there was a belief that social scientists could actively support such an endeavour because they were able to make a 'logical and objective assessment of the computer environment and its impact on human beings' (ibid. p. 325-326). Such beliefs are consistent with the sociotechnical approach, pioneered by members of the Tavistock Institute in London, and developed and modified by Mumford and colleagues in the UK (Mumford and Weir, 1979) and several researchers in Scandinavian countries (Hedberg, 1980; Kyng and Mathiassen, 1982; Ehn and Sandberg, 1983).

In contrast to critical orientations that were to emerge later on, Mumford and Sackman were significantly concerned with preserving the status quo, at least in terms of how they perceived it to exist within a democratic industrial society: specifically, they sought improvements in the quality of working life, rather than a transformation of society. Nevertheless, they were alert to the conflicting interests that would attend such an effort, to the extent that their view of criticality rested in urging social scientists to engage actively with the trades unions so that workers would have a key mediating role on the process of technological change. In later years, weaknesses in the socio-technical position started to emerge. Surplus labour, the rise of global capitalism, and moves including legislation in some countries - to curb the influence of the trades unions meant that the socio-technical design approach was increasingly abandoned (Kyng, 1998; Mumford, 1999, 2000). But being unprepared for a harsher commercial climate was only one of its weaknesses: the idealistic pursuit of logical, objective knowledge left it open to being subsumed within a managerialist discourse, but also ill placed to 
grasp the opportunities for influencing the course of IS innovation during use as well as during design (Avgerou, 2002).

\subsection{An emancipatory view}

Revealing a belief in consensus decision making and a concern with democratization of the workplace and society, an emancipatory view of criticality shares some similarities with a socio-technical approach. However, there are also major differences: specifically, the emancipatory tradition is openly critical of the status quo, seeing the need to transform society to achieve a 'better' life for all, and is sensitized to the way that structural forces - again, largely as perceived in Western industrial societies mediate the transformation efforts.

The emancipatory view emanated from the Institute of Social Research in Frankfurt, but has been specifically associated with the work of Jurgen Habermas, whose approach may be differentiated from theoretical positions adopted by other prominent members of the Frankfurt School, including Horkheimer, Adorno and Marcuse. Overall, these scholars sought to develop a historically grounded social theory that could be used to practical effect in real world situations. They sought to free human subjects from oppressive regimes within societies and within the institutions that constitute them. They believed that conscious human action could bring about the required changes, albeit in a situation mediated by institutional, historical and market forces. Habermas' approach to the critical project is characterized by a concern with linguistic and hermeneutic issues, and therefore with the role of language in societal development, rather than with a critique per se of western industrial life, its consumerist logic or instrumental reason (Laughlin, 1987). Unlike his contemporaries in the Frankfurt School, Habermas does not compare society to a predefined ideal state, from which it is judged to fall far short. Rather he tries to define the ideal conditions in which such an evaluation may take place. Moreover, Habermas provides considerable detail about the requisite conditions for ideal speech, and in this way his methodological approach is more comprehensive than the generalized critiques of Western society provided by his colleagues.

Laughlin (ibid.) argued that these features of Habermas' work provided a promising vehicle for critical accounting research. Similarly, critical research in information systems during the 1980s emphasized the insights that could be gained from a Habermasian perspective (see, for example, Lyytinen and Klein, 1985; Lyytinen and Hirschheim, 1988; Ngwenyama, 1991). Nevertheless, the research that followed seemed to acknowledge the weaknesses of an approach that seeks to remove the distorters of communication without having adequate mechanisms to analyse the power relations that gave rise to them in the first place (Lyytinen, 1992; Flyvbjerg, 1998). This work called for complementarism in critical research, by incorporating ideas from Foucault and Giddens alongside a Habermasian perspective (see also Mingers, 1992).

Others have argued that while critique of the status quo is highly appropriate, the emancipatory enterprise was a product of space and time. The optimistic, some would say utopian, nature of these narratives and their "totalizing" tendencies (Alvesson and Willmott, 1992) may be understood as a response to a Nazi regime, from which members of the Frankfurt School fled into exile in the United States in the mid-1930s (Burrell, 1994). In a transformed but still divided world, eclectic views of criticality seem better able to address the key role of context in framing what is considered 
rational and desirable (Avgerou and Madon, 2004) and to account for the grossly uneven processes of IS innovation in a global context (Walsham, 2001; Avgerou, 2002).

\subsection{Towards an eclectic view}

Some measure of the diverse views of criticality that now have currency are given by the following citations. Alvesson and Deetz (2000) identify three concerns of the critical researcher - insight arising from hermeneutic understanding, critique produced through genealogy and deconstruction, and transformative redefinition to open up new ways of engaging the social world. They argue:

Critical research may have different emphases; interpretive work aiming for insight may be central, complemented by limited elements of critique and transformative redefinitions. Critique may also dominate, but if so the empirical case study is typically used for more limited, illustrative purposes. Transformative redefinition should not dominate empirical research. Texts dominated by this tend to be Utopian and this quality is not salient in studies with research ambitions (p. 153).

This description suggests a broad definition of critical work, in which the role of achieving transformative or emancipatory effects is not our only or even our most immediate goal. It incorporates the Habermasian position that has been so popular in IS and related disciplines (for example, Lyytinen and Klein, 1985; Laughlin, 1987; Lyytinen, 1992; Mingers, 1992; Hirschheim and Klein, 1994), but it also includes a number of other positions, including the view that interpretive work may be critical.

Along similarly inclusive lines, Walsham (2003) cites from Saren and Brownlie (1999) to argue for a broad definition of critical IS research and of the type of theories that might be brought to bear in critical studies:

By critical perspectives we mean modes of theorising and research practices which regard knowledge and its related technologies as socially constructed and enacted; which take those practices to be historically and culturally contingent; and which are understood to shape and be shaped by vested interests and power.

By critical theory we mean any approach drawing inspiration from the substantive critical traditions of, for example, feminism, Marxism, ethnography and symbolism, poststructuralism, hermeneutics, postmodernism and environmentalism.

In the above definition of critical perspectives we see social constructionist concerns - the focus of interpretive research (Walsham, 1993) - alongside issues of historical and cultural contingency and power relations - a major concern for critical researchers (Orlikowski and Baroudi, 1991). In the definition of critical theory we see a number of approaches where the critical agenda is overt; others where the argument would be that which voices are lost is situational; and some where the emphasis might be on gaining interpretive understanding. Moreover, Walsham (2003) made his address to a culturally diverse audience - a joint meeting of Working Groups 8.2 and 9.4 of the International Federation of Information Processing (IFIP) - so his discussion of the ideas of Mahatma Gandhi and Nelson Mandela was apposite. Indeed, he accepted a view from the audience suggesting that some critical researchers might find these ideas more useful in their work than the predominantly Western inspired perspectives cited above. 
Clearly, how we view the nature of being critical has changed over time. While advocates of a social democratic view of criticality sought to achieve their effects through action research interventions in the process of technology innovation, proponents of an emancipatory view focused on developing a theoretical position for the IS discipline. In effect, the socio-technical approach sought to validate its concepts and ideas through practice (Mumford, 2000), while the emancipatory effort was (as others have argued about the works of Habermas) speculative until empirically tested (Burrell, 1994) . Most notably, in the context of this paper, there is little scope in most emancipatory writings for learning about the practice of doing critical research. More recently, the body of empirical critical work has increased; its authors are less inclined to argue that there is a universally desirable state of affairs, and in turn the research draws upon a more diverse range of theoretical resources. Nevertheless, this effort to acknowledge diversity in critical research is not matched by an interest in abstracting from its practice to inform our research methods. In effect, we have put much effort into defining the nature of being critical, but largely ignored opportunities for learning how criticality is achieved.

\section{ON ACHIEVING CRITICALITY}

At this point it is appropriate to ask what resources and guidance are available to those who wish to engage in critical research. What do we know already about linking theory and research practice through method in pursuit of a critical agenda, and what are the key unresolved issues?

In the last section I showed how prevailing views of criticality incorporate the position that interpretive work may be critical. Throughout the 1990s, the IS discipline produced a body of interpretive work. Moreover, IS and organizational researchers have drawn from empirical work to reflect on research practice in a number of writings about interpretive research methods (for example, Golden-Biddle and Locke, 1993; Walsham, 1993, 1995; Klein and Myers, 1999). Still, interpretive work is no more than an interpretation unless it has a limited critique. More controversially, perhaps, I suggest that critical work may be 'less than' interpretive. Finally, I suggest that these issues are not purely epistemological.

For example, Orlikowski's (1996) study of organizational transformation is a much cited example of interpretive work aiming to show how a group of customer service staff experimented with Lotus Notes in an incremental and improvisational process that gave rise to innovation and learning within the organization. Yet one may argue that the result of this emergent change was to produce a work process that was increasingly control oriented in a Foucauldian sense (cf. Lin and Cornford, 2000). Orlikowski addresses the interpretive concerns of understanding human agency as embedded in social context and viewing knowledge as a social construction (Walsham, 1993), but she does not problematize what was driving the transformation effort (Avgerou and McGrath, forthcoming). One form of a limited critique would question whether an outcome increasing managerial control was desirable to all. In effect it would challenge

\footnotetext{
${ }^{1}$ In 1992, Lyytinen concluded that IS research had made modest progress in applying a critical perspective based on the works of Habermas. He called for more empirical studies, but this work (for example, Ngwenyama and Lee, 1997; Myers and Young, 1997, Cecez-Kecmanovic, 2001) has been slow to materialize.
} 
Orlikowski's assumption that, whatever their tactics, actors constructed reality in terms of an overall goal of achieving organizational effectiveness, hence economic success of the firm (ibid.).

How actors are constituted, historically and culturally, may provide key questions for interpretive researchers with critical intent, but when such questions have a very focused structuralist effect on a critical agenda they may limit interpretation to the extent that it is unconvincing. For example, Hofmann (1999) argues that word processing software of the late 1970s and early 1980s was based on an image of the user that shows gender bias. Yet the design features to which she objects (for example, several levels of menu imposing rigid structure on female secretaries) were pervasive features of most commercial applications of the period (McGrath, 2003), including the investment banking and insurance underwriting applications used by predominantly male managers in London's financial institutions. Hofmann's feminist agenda fails to take account of the naïve way that systems developers of the time constituted the capabilities of 'users' - without regard to the user's gender or status - nor does it address how the limitations of hardware and software affected the design of commercial systems.

Of course, the above arguments support the position that ' $[\mathrm{t}]$ heory is both a way of seeing and a way of not-seeing' (Walsham, 1993, p. 6), but they are also a way of introducing the notion that theory and practice need to inform each other (ibid., p. 7), in this case with regard to the conduct of critical research. Two readings are important in showing that the issues raised are methodological as well as epistemological.

First, Klein and Myers (1999) describe seven interdependent principles for conducting and evaluating interpretive field studies in information systems. In the interpretive studies they examined, they found a strong theoretical basis (principle four), which prompted researchers to take account of historical and cultural context (principle two), and to search for multiple interpretations (principle six) while being suspicious of all of them (principle seven). Nevertheless, they also found that the way researchers came to decide upon the theoretical concepts that would inform their work (principle five), and how researchers and research subjects were constituted and transformed in their interactions during the research (principle three) are poorly addressed. Overall, they suggest that these studies - considered exemplars of interpretive field research in information systems (ibid. p. 84) - give at most moderate attention to the overarching concern of interaction between the totality and the parts (principle one). What Klein and Myers are addressing is a process in which the search for meaning must at some time confront the need to decide upon a theoretical perspective from which to attempt a coherent account - a point at which hermeneutics faces structuralism and the researcher must decide how to respond.

Dreyfus and Rabinow (1982) argue that Foucault addressed this issue by going 'beyond structuralism and hermeneutics'. In essence, they suggest that Foucault's work shows that he was aware of how he and his subjects were constituted by it, but also that he was able to achieve some distance from what he found in order to make a pragmatic reading. In other words, Foucault made an interpretation without being driven by the hermeneutic search for deep meaning, but also produced critique without appealing to an essential theory of human nature, or invoking general formulae or universal categories for analysis. Whether one accepts that Foucault achieved such a pragmatic project is not our question here. Rather I argue that dealing with a combination of hermeneutic and structuralist issues is an important and non-trivial task for critical 
researchers, in which I include interpretive researchers with critical intent. Moreover, I focus on longitudinal studies and ethnographies, not only because these tend to be critical researchers' methods of choice (Orlikowski and Baroudi, 1991), but also because they are a way of conducting interpretive research (Klein and Myers, 1999) which may produce elements of critique.

The methodological issues, then, are not the rather straightforward matters of whether to do interviews, observation, or both; with whom; and for how long: these details are not unimportant, but documenting them alone does no more than conform to the static positivist model that critical researchers claim to reject. The issues for critical research are those concerned with how research conduct is a response to the unfolding pattern of research findings; the way that researchers and their subjects are changed in the process; and how researchers achieve critical distance. The first two issues are those that Klein and Myers (1999) found to be largely ignored in the interpretive studies they examined. Moreover, they argue that in the study they found to have the most critical orientation greater attention was given to contextualizing the research - historically and culturally - and to exercising suspicion of all narratives. While such contextualization and suspicion may be seen as defining traits of a critical researcher, I suggest that at some point a critical researcher must break out of the hermeneutics of suspicion to problematize the observed behaviours. In the Foucauldian spirit suggested by Dreyfus and Rabinow (1982), they must find a way to present an account that neither relies solely on what the research subjects say, nor expects to unearth 'a different and deeper meaning of which the social actors are only dimly aware' (p. xx).

In short, Klein and Myers principles are useful for critical as well as interpretive research, but where critique is a goal some principles will likely be emphasized more than others, and researchers must be prepared to abandon the hermeneutic search for deep meaning. Without claiming that critical researchers give insufficient thought to their research conduct, I argue that their accounts of research methodology show limited evidence of it. I suggest that they must, so that critical researchers can not only reject the positivist model, but also establish their credentials in a methodological sense, and reach a position where the theory and practice of critical research inform each other.

\section{TWO EXAMPLES OF CRITICAL RESEARCH}

In this section I examine two key texts in which the authors subscribe to a critical agenda, so that I may ask what research practice can learn from them. The texts I have chosen are Making a World of Difference: IT in a Global Context (Walsham, 2001) and Information Systems and Global Diversity (Avgerou, 2002) for the following reasons. First, the authors explicitly claim to have a critical agenda, but they pursue it in different ways. Second, these books have been widely acclaimed within the IS community, and by scholars in other disciplines: reviews suggest that they provide insight and critique on the adoption and use of information and communication technologies (ICTs) in a global context (Boland and Hirschheim, 2001; Ramiller, 2003; Sahay, 2003). Third, the books have a substantive empirical content, with some supporting details of the authors' research methodologies. I examine both texts by reference to the ideas outlined in previous sections. 


\subsection{The nature of being critical}

Broadly speaking, both Walsham (2001) and Avgerou (2002) adopt a critical perspective to examine the processes of ICT innovation and organizational change in a global context, but a key difference is the combination of insight and critique sought by the authors (Alvesson and Deetz, 2000). Walsham develops in-depth field studies to raise awareness of our differences, and to appeal to us to celebrate them. The search for insight is central, but it is complemented by a critique arguing that there are aspects of a multicultural world that are unacceptable, such as the stark asymmetries of wealth and power among different groups. Walsham aspires to some transformation - making a better world with IT - and he challenges us to engage with this effort, primarily because he believes we should be morally concerned, but also because globalization has consequences for all of us, so doing nothing is not an option.

Avgerou uses case studies to illustrate a critique addressing the marginalization of diverse interests in the unfolding of ICT innovation and organizational change in a global context. Critique is central to her effort to bring to consciousness the restrictive conditions of the current socio-economic order, but it is supported by four case studies that highlight the need for a context-specific analysis of how those conditions come to bear on a particular innovation effort. Avgerou lays claim to a pragmatic position, in which she evaluates IS innovation in terms of its practical consequences in a particular context. In this way, she eschews proposing a particular quality of social order, but challenges us to reexamine our assumptions with the claim that none of democracy, emancipation or economic development is universally desirable.

\subsection{Achieving criticality}

Walsham and Avgerou have a strong theoretical basis to their work (Klein and Myers, 1999, principle four), but neither appeals to an essential theory of nature or society. Rather their use of theory is eclectic, intended to reflect the diversity of contexts they studied and the uneven way in which IS innovation has unfolded in a global context. Both authors contextualize their research (ibid. principle two), pay attention to multiple viewpoints (ibid. principle six), but make their own sense of them (ibid. principle seven), asserting that in the final analysis the interpretation is their own. Nevertheless, the emphasis they give to the particular principles of the hermeneutic process highlighted above varies in each case.

Walsham makes a very eclectic use of concepts, guided by his concern to examine issues at individual, group, organizational, interorganizational and societal levels. He uses extensive commentary from his research subjects to support arguments that are none the less his own because he has selected which commentaries to include and the theoretical concepts through which they will be presented. His emphasis is on showing the multiple viewpoints, and the range of ideas that can be used to understand them, supported by a strong assertion in his methodology section that his is an - and not the interpretation. This approach gives a rich picture of life at individual, group and organizational levels, but less detail about the socio-economic and political conditions in which that life is embedded.

Avgerou emphasizes how the IS innovation processes she describes were shaped historically and culturally. Strongly, but not solely, influenced by institutionalist theory, she examines in some detail the socio-political and economic conditions in which the 
innovations took place and how those conditions were constituted over many years. Her methodology appendix states that she interviewed her research subjects, but she makes no use of commentary from them, seeking to convince us of her claim that these innovation efforts were intensely negotiated through her detailed descriptions of historical and cultural context. This approach provides a rich picture of life in terms of organizational, national and, to some extent, cross-national layers of analysis, without making use of 'talking subjects' to comment on how the conflicts arising came to bear on them personally.

In terms of the four principles examined so far, Walsham makes strong links between theory and multiple interpretations, while Avgerou emphasizes the relationship between theory and historical and cultural context. From the case descriptions, as well as the authors' own claims to making an interpretation, it is clear that neither Walsham nor Avgerou took the commentaries of their research subjects at face value. What, then, do they say about how they broke out of the hermeneutics of suspicion to decide upon the theoretical concepts that would inform their work (principle five), and how they and their research subjects were constituted and transformed in their interactions during the research (principle three)? On these issues, the authors' descriptions of their research methodology are short on detail, but again in different ways.

Walsham states that his methods were informed by an interpretive stance, a subject on which he has already contributed (Walsham, 1993, 1995), but he includes Making a World of Difference within a broad definition of critical research (Walsham, 2003). How, then, should we understand the way that an interpretive stance can ultimately give rise to critical research? If we accept Walsham's claim that his field studies were conducted using interpretive methods, and for the most part this is the way he reports on them in his journal papers, then how did he achieve criticality in his book?

I suggest that when writing the book he engaged in a problematization of what was driving these IS innovation efforts, so as to consider the diverse ways in which globalization has consequences for everyone. The work involved to do this was no mechanistic 'cut and paste job' from his journal papers, but it was part of his research methodology for the book. It also involved examining field studies in which he did not participate, and in these cases he says that he sought comments from other authors, and sometimes modified his interpretation of their research in response to replies received. His motivations for doing this work are made clear in the book's Preface, but it would be instructive to know more about the effort involved to reconsider a decade of research and present it with critical intent, and how he and his collaborators were changed in the process. If research methodology is a cause that deserves our attention, and Walsham's publication record suggests that he finds it so, then critical research would surely benefit from such an undertaking.

Avgerou, on the other hand, makes no direct appeals in her methodology appendix to the assumptions of a particular research philosophy, but elsewhere in her book she lays claim to a critical perspective. Still, her methodology section resembles the static accounts of research conduct we might expect to find in the normative research she so explicitly rejects throughout the main body of her book. The format of this section and its relegation to an appendix not only runs counter to the considered way she presents the epistemological foundations of her work, but also contradicts the structurationist approach she adopts elsewhere by giving the impression that she believes epistemology and methodology are separable. 
One needs to look elsewhere to discover more about Avgerou's methodological effort. In the Preface to her book, she describes how her doctoral students, who were sometimes more familiar than her with the cultural context of particular cases, challenged her views and influenced her interpretations. She also shows how students participating in her graduate seminars on 'IT in Developing Countries' informed her effort over many years. When one compares how she reported on some of the cases in her journal papers (Avgerou, 2000, 2001), we see that they are transformed in the book, with considerably more attention to the socio-political and economic conditions of particular nations. In the book chapters, Avgerou's style seems to owe much to the 'strong textualist' approach of Foucault (Rorty, 1982, cited in Golden-Biddle and Locke, 1993), in which descriptions of the historical and cultural contexts dominate. Her methodological approach also seems to be a Foucauldian-inspired effort to go 'beyond structuralism and hermeneutics' (Dreyfus and Rabinow, 1982), in the manner described earlier. Avgerou might tell us more of this effort by abstracting from her own research conduct to inform research practice, rather than subscribing reluctantly to a normative model of documenting methodology in which she surely does not believe.

Although following a positivist model for documenting research conduct may be an indication that authors are conforming to the normative pressures of a particular journal (Klein and Myers, 1999), these pressures are often less intense when writing a book. However, '[s]elf-reporting faces the twin dangers of over-modesty and selfaggrandisement, and it is particularly difficult to steer a middle path between these two extremes' (Walsham, 1995, p. 78). This is perhaps why Walsham and Avgerou leave some details to our imagination when they document their research conduct, the more so because the type of reflexivity that characterizes critical research might make that reporting especially prone to such dangers. Nevertheless, established colleagues do not become so without facing these dangers in other aspects of their work: lessons they have learned along the way can surely only help those whose reputations are still in the making.

\section{DISCUSSION}

This research suggests that broad definitions of the nature of being critical have currency within the IS discipline, that the body of empirical critical work is increasing, but that we are not making the most of opportunities to learn from our efforts to date, which retards further development. These findings inform the way I seek to develop this research in three ways. First, broad definitions of critical perspectives suggest that, starting from a position that interpretive research may be critical, we might explore how to make more use of existing research models, and the potential they offer for guiding the conduct and evaluation of critical research. Such an effort at reuse has a precedent, as Walsham (1995) reminds us when he elaborates Eisenhardt's (1989) positivist model in his paper on the nature and method of interpretive research. Second, the broad definitions outlined earlier suggest that issues, as much as theories, are key to the nature of critical research. Ironically, positivism has a further lesson for us, since many positivist researchers would argue that it is their focus on issues that drives their research efforts and accords them relevance. Within critical research, however, we might strive for a combination of issues and theories that accepts several models for conducting and evaluating critical work, rather than trying to derive a uniform set of 
guidelines that risks being too general to be helpful or too riven with contradiction to be useful. Third, since much conceptual critical work has now been undertaken within the IS discipline, and empirical critical work is on the increase, we have an opportunity to evaluate what we have learned so far and suggest further developments.

The two books I have examined in this paper adopt different ways of pursuing a critical agenda. Both authors' critical issue is the uneven way in which IS innovation unfolds in a global context, and each is particularly concerned with the consequences for less developed economies. Walsham draws from a very broad range of social theories, although Giddens' influence is a continuing theme. Avgerou is influenced by Foucault, arguably more strongly than her rather short discussion of his work would suggest. In terms of the emphases in their work (Alvesson and Deetz, 2000), Walsham focuses on achieving insight arising from hermeneutic understanding, whereas Avgerou directs her effort to producing critique. Walsham approaches his task by making strong links between theory and multiple interpretations (Klein and Myers, 1999, principles four and six), which gives a richer picture of life for individuals and groups than it achieves at broader societal levels of analysis (ibid. principle two). Avgerou uses theory to present a detailed account of particular IS innovation efforts, in which descriptions of the historical, organizational and socio-economic contexts dominate (ibid. principles four and two). But, as with the 'strong textualist' style of Foucault's work, she leaves us to speculate on what the subjects of these organizing regimes would say if she had included their commentaries (ibid. principle six).

The authors' different emphases on insight and critique seem to account for the way they approach their work in an epistemological sense. Methodologically, however, we have to work harder to understand their achievements. I argue that Walsham and Avgerou provide some evidence of the efforts required to achieve their effects, but not enough detail to enable us to learn as much as we could from them. The authors document only partially the dynamics of the research process - how it was a response to the unfolding pattern of research findings; how they and their research subjects were changed in the process; and how critical distance was achieved (ibid. the relationship among principles three, five and seven). However, these are the aspects of critical research about which we know the least, not only because empirical work is lagging conceptual efforts, but also because we are not making the most of our opportunities to reflect on the field studies we undertake.

As Smircich observed about the key questions for non-positivist researchers of organizational culture: the task is not to say 'what is organizational culture?', with a view to prescribing how organizations can create a desirable one; rather it is to ask 'how is organization accomplished, and what does it mean to be organized?' (1983, p. 353). In a similar manner, I argue that we have spent some time already asking 'what is critical research?'; we now need to shift attention to examine the examples we have, with a view to understanding how such research is accomplished and what it means to be critical. In this effort, we need to give as much attention to documenting our methodological approach as to explicating the epistemological foundations of our work.

In summary, I do not try to develop a model for conducting and evaluating critical research. Rather, I take some answers we have provided to the question 'what is critical research?' and explore what they mean for the nature and method of doing critical work. In this paper, I raise more questions than I alone can hope to answer, but perhaps that is not a bad model for an aspiring critical researcher. My message is one of appealing to colleagues not just to engage in more empirical work, but to use the opportunities it 
provides to reflect on research conduct. In my concluding section I give some reasons why I think such an effort is important.

\section{CONCLUSION}

I have argued that the theory and practice of conducting critical IS research do not seem to be informing each other. Specifically, when critical researchers report on their field studies, their descriptions of methodology (where these are provided at all) show few, if any, distinguishing traits from those of interpretive or positivist researchers. Yet to produce a substantive critique, some additional or different research practices must take place. While these practices remain unstated or implicit, critical researchers will continue to identify few methodological contributions and critical methods will remain underdeveloped. Why does this matter?

First, there are few examples of empirical critical research relative to either interpretive or normative studies. Although interpretivism has done much to challenge the dominant normative IS literature and practice, I suggest that deep understanding and rich description can only take us so far. Critical research, potentially at least, offers a promising approach for addressing some of the complex and thus far intractable issues we face today. Yet doctoral students, as one source of potential critical researchers, usually decide not to pursue a critical project, even when their supervisors conduct critical research. Supervisors may argue that this is because they give their students room to find their own approach, but might it not also be because their students can usually find more guidance in the literature on how to conduct an interpretive or normative project? Over time, are we reinforcing other approaches and keeping critical research on the sidelines simply because the latter is too difficult for us?

Second, critical researchers may argue that reflecting upon (rather than just documenting) research methods is virtually absent in the dominant forms of research notably the hypothetico-deductive approach - so why should they do more or subscribe to a normative regime in which they do not believe. How we criticize those "allknowing" researchers, who develop their theoretical frameworks up front and then seem to find no reason to reconsider them during empirical work. Can we really expect those who tell part of the story to take our criticism seriously if we say even less about our research conduct? And don't some of us sometimes publish rather indiscriminately, presenting the same study from a number of slightly differing perspectives, so that which reading said what tends to blur in our readers' minds even if they do not in our own recollection? Is it unthinkable that we might reconsider our publication strategies and take the time needed to reflect on research conduct, in the interest of publishing both good examples for colleagues starting out and work for which we would like to be remembered?

Third, it is hardly news to argue that certain journals (seen by many as the 'top' journals in our field) will not publish work that omits a detailed description of research methods. Walsham (2003) has already encouraged us to try to infiltrate outlets such as MIS Quarterly with critical studies. For those who would publish elsewhere rather than submit to what they perceive to be a normative regime, I have this appeal. Write an occasional paper on method for your journal of choice. I have no desire to encourage lengthy confessional accounts of research conduct in all journal papers - some of us would simply not say anything new. But if journals with a track record of publishing 
critical work aspire to wider readership and higher rankings, can it harm their case if they can show that their contributors are sophisticated in a methodological sense?

Finally, I said at the outset that critical researchers often have a cause. This paper would give us all another one - the cause of method - so that whatever else we hope to bring to consciousness we do it more convincingly.

\section{REFERENCES}

Adam, A., Howcroft, D., Richardson, H. and Robinson, B. (eds.) (2001) Proceedings of an International Workshop on (Re-) Defining Critical Research in Information Systems, University of Salford, UK, July.

Alvesson, M. and Deetz, S. (2000) Doing Critical Management Research, Sage, London.

Alvesson, M. and Willmott, H. (1992) "On the idea of emancipation in management and organization studies," Academy of Management Review 17(3), pp. 432-464.

Avgerou, C. (2000) "IT and organizational change: An institutionalist perspective," Information Technology and People 13(4), pp. 234-262.

Avgerou, C. (2001) "The significance of context in information systems and organizational change," Information Systems Journal 11, pp. 43-63.

Avgerou, C. (2002) Information Systems and Global Diversity, Oxford University Press, Oxford.

Avgerou, C., Ciborra, C. and Land, F. (eds.) (2004) Social Study of Information and Communication Technology, Oxford University Press, Oxford.

Avgerou, C. and Madon, S. (2004) "Framing IS studies: Understanding the social context of IS innovation," in Social Study of Information and Communication Technology, C. Avgerou, C. Ciborra and F. Land (eds.), Oxford University Press, Oxford.

Avgerou, C. and McGrath, K. (forthcoming) "Rationalities and emotions in IS innovation," in Handbook of Information Systems Research: Critical Perspectives on Information Systems Design, Implementation and Use, D. Howcroft and E. Trauth (eds.), Edward Elgar, Cheltenham.

Boland, R. and Hirschheim, R. (2001) "Series preface," in Making a World of Difference: IT in a Global Context, G. Walsham, Wiley, Chichester.

Burrell, G. (1994) "Modernism, postmodernism and organizational analysis 4: The contribution of Jurgen Habermas," Organization Studies 15(1), pp. 1-19.

Cecez-Kecmanovic, D. (2001) "Critical information systems research: A Habermasian perspective," in Proceedings of the $9^{\text {th }}$ European Conference on Information Systems, S. Smithson, J. Gricar, M. Podlogar and S. Avgerinou (eds.), Moderna Organizacija, Kranj, Slovenia.

Dreyfus, H. and Rabinow, P. (1982) Michel Foucault: Beyond Structuralism and Hermeneutics, Harvester-Wheatsheaf, Hemel Hempstead, UK.

Ehn, P. and Sandberg, A. (1983) "A local union influence on technology and work organization: Some results from the DEMOS project," in Systems Design For, With and By the Users, U. Briefs, C. Ciborra and L. Schneider (eds.), North-Holland, Amsterdam.

Eisenhardt, K. (1989) "Building theories from case study research," Academy of Management Review 14(4), pp. 532-550. 
Flyvbjerg, B. (1998) "Empowering civil society: Habermas, Foucault and the question of conflict," in Cities for Citizens, M. Douglass and J. Friedmann (eds.), Wiley, New York.

Golden-Biddle, K. and Locke, K. (1993) "Appealing work: An investigation of how ethnographic texts convince," Organization Science 4(4), pp. 595-616.

Hedberg, B. (1980) "Using computerized information systems to design better organizations and jobs," in The Human Side of Information Processing, N. BjornAndersen (ed.), North-Holland, Amsterdam.

Hirschheim, R. and Klein, H. (1994) "Realizing emancipatory principles in information systems development: The case for ETHICS," MIS Quarterly 18(1), pp. 83-109.

Hofmann, J. (1999) "Writers, texts and writing acts: Gendered user images in word processing software," in The Social Shaping of Technology, D. MacKenzie and J. Wajcman (eds.), $2^{\text {nd }}$ edition, Open University Press, Buckingham.

Klein, H. and Myers, M. (1999) "A set of principles for conducting and evaluating interpretive field studies in information systems," MIS Quarterly 23(1), pp. 67-93.

Kyng, M. (1998) "Users and computers: A contextual approach to design of computer artifacts," Scandinavian Journal of Information Systems 10(1\&2), pp. 7-44.

Kyng, M. and Mathiassen, L. (1982) "Systems development and trade union activities," in Information Society, for richer, for poorer, N. Bjorn-Andersen (ed.), NorthHolland, Amsterdam.

Laughlin, R. (1987) "Accounting systems in organizational contexts: A case for critical theory," Accounting, Organizations and Society 12(5), pp. 479-502.

Lee, A., Liebenau, J. and DeGross, J. (eds.) (1997) Information Systems and Qualitative Research, Chapman and Hall, London.

Lin, A. and Cornford, T. (2000) "Socio-technical perspectives on emergence phenomena," in The New Sociotech: Graffiti on the Long Wall, E. Coakes, R. LloydJones and D. Willis (eds.), Springer-Verlag, London.

Lyytinen, K. (1992) "Information systems and critical theory," in Critical Management Studies, M. Alvesson and H. Willmott (eds.), Sage, London.

Lyytinen, K. and Hirschheim, R. (1988) "Information systems as rational discourse: An application of Habermas' theory of communicative action," Scandinavian Journal of Management 4(1/2), pp. 19-30.

Lyytinen, K. and Klein, H. (1985) "Critical theory of Jurgen Habermas as a basis for a theory of information systems," in Research Methods in Information Systems, E. Mumford, R. Hirschheim, G. Fitzgerald and T. Wood-Harper (eds.), North-Holland, Amsterdam.

McGrath, K. (2003) "Organisational culture and information systems implementation: A critical perspective," Unpublished Ph.D. Dissertation, London School of Economics, UK, http://is.lse.ac.uk/research/theses/mcgrath.pdf.

Mingers, J. (1992) "Technical, practical and critical OR - past, present and future?" in Critical Management Studies, M. Alvesson and H. Willmott (eds.), Sage, London.

Mumford, E. (1999) "Routinisation, re-engineering and socio-technical design: Changing ideas on the organisation of work," in Rethinking Management Information Systems, W. Currie and R. Galliers (eds.), Oxford University Press, Oxford.

Mumford, E. (2000) "Socio-technical design: An unfulfilled promise or a future opportunity," in Organizational and Social Perspectives on Information Technology, R. Baskerville, J. Stage and J. DeGross (eds.), Kluwer, London. 
Mumford, E., Hirschheim, R., Fitzgerald, G. and Wood-Harper, T. (eds.) (1985) Research Methods in Information Systems, North-Holland, Amsterdam.

Mumford, E. and Sackman, H. (eds.) (1974) Human Choice and Computers, NorthHolland, Amsterdam.

Mumford, E. and Weir, M. (1979) Computer Systems in Work Design - The ETHICS Method, Associated Business Press, London.

Myers, M. and Young, L. (1997) "Hidden agendas, power and managerial assumptions in information systems development: An ethnographic study," Information Technology and People 10(3), pp. 224-240.

Nissen, H-E., Klein, H. and Hirschheim, R. (eds.) (1991) Information Systems Research: Contemporary Approaches and Emergent Traditions, North-Holland, Amsterdam.

Ngwenyama, O. (1991) "The critical social theory approach to information systems: Problems and challenges," in Information Systems Research: Contemporary Approaches and Emergent Traditions, H-E. Nissen, H. Klein and R. Hirschheim (eds.), North-Holland, Amsterdam.

Ngwenyama, O. and Lee, A. (1997) "Communication richness in electronic mail: Critical social theory and the contextuality of meaning," MIS Quarterly 21(2), pp. 145-167.

Orlikowski, W. (1996) "Improvising organizational transformation over time: A situated change perspective," Information Systems Research 7(1), pp. 63-92.

Orlikowski, W. and Baroudi, J. (1991) "Studying information technology in organizations: Research approaches and assumptions," Information Systems Research 2(1), pp. 1-28.

Ramiller, N. (2003) “Book reviews: 'Information Systems and Global Diversity' by Chrisanthi Avgerou," Information Technology and People 16(2), pp. 235-240.

Rorty, R. (1982) The Consequences of Pragmatism, University of Minnesota Press, Minnesota.

Sahay, S. (2003) "Book reviews: 'Information Systems and Global Diversity' by Chrisanthi Avgerou," Information Technology and People 16(2), pp. 240-246.

Saren, M. and Brownlie, D. (1999) "Introduction to the marketing stream," in Proceedings of the $1^{\text {st }}$ Critical Management Studies Conference, H. Willmott and I. Grugulis (eds.), University of Manchester Institute of Science and Technology, UK.

Smircich, L. (1983) "Concepts of culture and organizational analysis," Administrative Science Quarterly 28(3), pp. 339-358.

Smircich, L. and Calas, M. (1987) "Organizational culture: A critical assessment," in Handbook of Organizational Communication, F. Jablin, L. Putnam, K. Roberts and L. Porter (eds.), Sage, Newbury Park.

University of Salford. (2001) An International Workshop on (Re-) Defining Critical Research in Information Systems, University of Salford, UK, July.

Walsham, G. (1993) Interpreting Information Systems in Organizations, Wiley, Chichester.

Walsham, G. (1995) "Interpretive case studies in IS research: Nature and method," European Journal of Information Systems 4(2), pp. 74-81.

Walsham, G. (2001) Making a World of Difference: IT in a Global Context, Wiley, Chichester. 
Walsham, G. (2003) "Development, global futures and IS research: A polemic," Closing Keynote Address to the IFIP WG 8.2 and IFIP WG 9.4 Conference, Athens University of Economics and Business, Greece, June. 